\title{
Physical Activity Interventions in School and their impact on Scholastic Performance
}

\author{
Ingegerd Ericsson* \\ Associate professor in Sport Sciences, Malmö University, Sweden
}

ISSN: 2577-1914

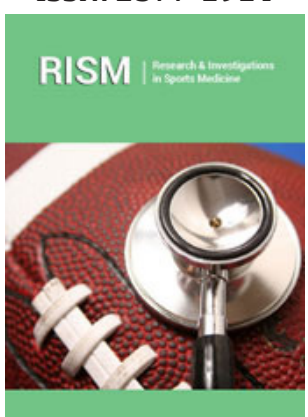

*Corresponding author: Ingegerd Ericsson, Associate professor in Sport Sciences, Malmö University, Nordenskiöldsgatan $\quad 10, \quad$ S-205 06 Malmö, Sweden

Submission: 制 April 20, 2020

Published: 酹July 23, 2020

Volume 6 - Issue 4

How to cite this article: Ingegerd Ericsson. Physical Activity Interventions in School and their impact on Scholastic Performance. Res Inves Sports Med, 6(4): RISM.000645. 2020. DOI: $10.31031 /$ RISM.2020.06.000645

Copyright@ Ingegerd Ericsson, This article is distributed under the terms of the Creative Commons Attribution 4.0 International License, which permits unrestricted use and redistribution provided that the original author and source are credited.

\begin{abstract}
The school is the only arena where the vast majority of children and youth can be reached, and school programs have had better results for improving inhibitory control than any other approach. The aim was to present and discuss intervention effects of Physical Activity (PA) carried out in the classroom compared to motor skills and Physical Education (PE) interventions.

Results from PA interventions in school are inconsistent, but PE interventions which include motor skills exercise seem to be the most promising. The main findings show that motor skills are a stronger predictor of scholastic performance than aerobic fitness. Aerobic exercise with a high level of physical exertion does not improve any cognitive function in children. Cognitive engagement in PA at a moderate level seems to be the most promising type of exercise. PA lessons do not seem to improve any executive function and classroom-based PA do not have a positive impact on scholastic performance. Although there is some evidence that a single session of moderate PA may improve cognitive performance among children, too intense levels of PA may blunt any beneficial effect. There is a lack of a theoretical basis as to why PA lessons may facilitate scholastic performance. What students are supposed to learn from physical activities in the classroom needs to be clarified.

An increase of the school subject PE and motor skills exercise can be a feasible to improve motor skills and scholastic performance in children and youth, especially when interventions are developed by trained PE teachers. Daily PE in combination with adapted motor skills support can improve not only motor skills but also scholastic performance and proportions of students who reach qualification for higher education. In addition the intervention would produce health-economic gains for society (reduced morbidity costs and productivity gains). Well educated PE teachers are essential for translating research findings into practice since they can properly design motor skill observations, PE programs, and motor skill programs in order to optimize their effect on children's cognition and scholastic performance.

Conclusion: There is limited and inconclusive evidence regarding effects of different PA interventions in school on cognitive functioning and scholastic performance. Moderate levels of PA with cognitive challenges are more effective than aerobic exercise. There is a strong association between motor competence and scholastic performance. PE interventions which include motor skills exercise seem to be more promising than PA in the classroom. Motor skills assessment early in school is associated with later school achievement and can be used as an indicator of children's future scholastic performance. Daily PE and adapted motor skills training can positively influence motor skills, higher grades and higher proportions of pupils who reach qualification for higher education.
\end{abstract}

Keywords: Fundamental motor skills; MUGI observation checklist; Physical education; The bunkeflo project; Executive functions; Brain breaks; Teacher education

\section{Introduction}

Although there is strong evidence for beneficial effects of physical activity (PA) on students' mathematic performance, there is currently inconclusive evidence for beneficial effects of PA on overall scholastic performance in children [1]. Many PA interventions are carried out in school, since the school is the only arena where the vast majority of children and youth can be reached [2]. Diamond and Ling [3] report that school programs have had much better results for improving inhibitory control than any other approach. PA, especially physical education (PE), benefits several aspects of academic achievement in youth, e.g. mathematics and reading. Results in a systematic review and meta-analysis shows that curricular exercise is the most effective PA intervention to improve children's and adolescents' academic achievement [4]. However, not all PA interventions in school have had positive results. The aim of this review is 
to present and discuss intervention effects of PA carried out in the classroom compared to motor skills and PE interventions.

\section{Motor Skills and the Cognitive Stimulation Theory}

Executive functions (EFs: inhibitory control, working memory, and cognitive flexibility) have a supportive linkage to scholastic performance and are often used as indicators of cognition and learning. EFs seem to be especially sensitive to coordinative and cognitive complex movements, through which PA might impact EF efficiency [5]. Evidence indicates that motor competence (MC) is positively associated with perceived competence and multiple aspects of health, i.e. PA, cardiorespiratory fitness, muscular strength, endurance, and healthy weight status [6]. In a crosssectional study by Schmidt et al. [7] showed that all aspects of motor ability (metabolic fitness, muscular fitness, and MC) predict academic achievement, but only the MC-academic relation is mediated by EFs. This means that there is a unique relation linking $\mathrm{MC}, \mathrm{EF}$ and scholastic performance. Well-developed gross motor skills can facilitate children's cognitive functioning [8] and higher levels of MC are associated with higher order cognitive function, working memory, and processing speed. Ludyga et al. [9] found higher working memory maintenance in adolescents with high MC compared to those with low MC. Children (11 years old) with low MC performed poorer on fitness tasks, were less physically active and had lower perception of athletic competence and social acceptance than children with high MC in a study by Vedul-Kjelsås et al. [10]. Westendorp et al. [8] compared gross motor skills of children (7-12 years old) who had learning disabilities $(n=104)$ with those of typically developing children. Children with learning disabilities scored poorer on both locomotor and object-control than their typically developing peers; the larger children's learning lag was, the poorer were their motor skill scores.

In a consensus conference 24 researchers from differentresearch areas concluded that mastery of fundamental motor skills (FMS) is beneficial to cognition and scholastic performance in children and youth [11]. A theoretical explanation is the cognitive stimulation hypothesis, which assumes that coordinative demanding PA (e.g. learning new motor skills, sports or coordinative skills) not only increases physical fitness, but also enhances higher-order cognitive control, i.e. EFs [12]. Learning new motor skills can be demanding, both coordinately as well as cognitively and it seems to be one way to improve cognitive functions, especially EFs.

An intervention focused on playful opportunities to develop and master motor skills. The results showed that young children $(n=118)$ after eight months of intervention had significantly better locomotor and object control skills as well as cognitive scores compared to a control group. The findings suggest that even limited exposure to a low intensity program for motor development can positively impact gross motor skills and cognitive function in preschoolers. The authors conclude that play and opportunities to develop and master FMS can increase levels of self-efficacy in motor skills to be used in sport exercising later in childhood and adolescence [13]. Effects of various PA programs on motor skills and cognitive development were examined in typically developed preschool children by Zeng et al. [14]. Of ten studies assessing the effects of PA on motor skills, eight reported significant improvements in motor performance. Of five studies investigating the impact of PA on cognitive development, four reported significant improvements in language learning, academic achievement, attention, and working memory.

In a systematic review by Macdonald et al. [15] statistically significant effects of motor skill interventions on academic performance compared to control groups were found in all four examined studies. Son and Meisels [16] included 12,583 children in US kindergartens and found that gross motor skills and visual motor skills were unique, significant predictors of first-grade reading and mathematics achievement; suggesting longitudinal relations between early motor skills and the skills in later cognitive achievement. Similar results were found by Ericsson [17] in the Swedish Bunkeflo project where long-term effects on motor skills and scholastic performance were studied. The intervention consisted of motor skills observations and daily PE $5 \times 45$ minutes/ week) for all students, and for children in need of it, 60 minutes/ week of adapted motor skills support according to the model Motor skills Development as Ground for Learning (in Swedish: Motorisk Utveckling som Grund för Inlärning) (MUGI) (Figure 1). Significant improvements were found in reading, writing and mathematics in the intervention compared to a control group [17]. The intervention was an effective way to improve not only motor skills but also scholastic performance.

Oberer et al. [18] found that visual-motor coordination was a stronger predictor for later academic achievement than physical fitness, suggesting that visual-motor coordination is of particular importance in the beginning of formal schooling when learning to write is not yet automatized. Children with better visual-motor coordination are thus at an advantage compared to children with less well-developed motor coordination. These findings support the hypothesis that motor skills are related to later cognitive achievement and that motor skills observations can be used to successfully identify children at risk for academic underachievement later in school.

Motor skills have been found to be a stronger predictor of academic achievement than aerobic fitness [19] and cognitively challenging PA (i.e. exercises that require complex, controlled motor skills) improves cognitive flexibility more than simple aerobic training [20]. Interventions over several weeks that include coordinately demanding and cognitively challenging PA seem to be more effective in improving EFs and cognitive performance than aerobic exercise [21,22]. An intervention among adolescents consisted of increased PA $20 \mathrm{~min} /$ day with focus on intense aerobic exercise and low cognitive demands. No effects were found on any EF. Sjöwall et al. [23] conclude that aerobic exercise with low cognitive load does not produce any improvements in EFs.

Cognitive performance might be influenced specifically by bilateral coordinative exercise [24]. In a meta-regression where 80 RCTs were included, one of the most influential moderators was exercise type, with coordinative exercise being most effective 
for improving cognitive function. Higher benefits of exercise on cognitive function were found after coordinative exercise than after other exercise types (endurance exercise, resistance training and mixed types). With longer intervention time (at least 22 weeks), the effect size increased with longer session duration (30-60 minutes) [25]. This meta-analysis also showed that exercise at low to moderate intensity were most beneficial for female students, whereas men could improve further from higher intensity. Koutsandréou et al. [22] examined the impact of aerobic compared to motor skills exercise on primary school children's working memory. Students in a control group had assisted homework sessions. Working memory benefited from both the aerobic and motor exercise programs, but not from the control condition. The increase in working memory was significantly larger for children in the motor exercise compared to the aerobic exercise group. Special motor demanding interventions seems to be a beneficial strategy to improve working memory in preadolescent children. Van der Fels et al. [26] suggest that complex motor skills such as fine motor skills, coordination of movement in rhythm, and sequenced movements should be included in PA intervention programs to improve higher order cognitive skills.

The main findings of motor skills interventions show that welldeveloped gross motor skills can facilitate children's cognitive functioning and higher levels of motor competence are associated with higher order cognitive function, working memory, and processing speed. Aerobic exercise with low cognitive load does not produce any improvements in EFs. Interventions over several weeks that include coordinately demanding and cognitively challenging PA seem to be more effective in improving EFs and cognitive performance than aerobic exercise. Motor skills have been found to be a stronger predictor of scholastic performance than aerobic fitness. Daily PE in combination with adapted motor skills support can improve not only motor skills but also scholastic performance.

\section{Physically Active Lessons and Brain Breaks}

Much research has focused on chronic, i.e. long-term PA interventions, rather than acute, i.e. single bouts of classroombased PA. Rathore and Lom [27] included eight chronic PA and seven acute PA studies in a meta-analysis and found statistically significant evidence that chronic PA improved working memory of healthy individuals while acute PA interventions did not. PA lessons (or PA learning) combine PA with scholastic content and are used to increase PA in school without decreasing educational time, e.g. to jump/skip while reciting or to use special movements to show an answer. The activity can be relevant to a specific learning task, or non-relevant but still conducted simultaneously in the learning session. PA lessons are not the same as brain breaks (or active breaks), which contain bouts of classroom activities without any learning content. Centers for Disease Control and Prevention reported that eight of nine studies found positive associations between classroom-based PA and indicators of cognitive skills as well as attitudes, academic behavior, and academic achievement. Most of the interventions used short breaks (5-20 minutes) that required little or no teacher preparation, special equipment, or resources [28]. However, Howie et al. [29] found no improvements in working memory or in a trial-making test after classroom active breaks. There were only small improvements in girls', but not in boys' mathematics performance after 10 and 20 minutes of exercise breaks (e.g., stationary marching, jumping or running in place).

No effect was found on any EF or mathematic skills in Danish adolescents after a PA intervention in a Randomized Controlled Trial (RCT). Tarp et al. [30] examined the effects of a 20 weeks intervention with PA during academic lessons, recess, school transportation, and leisure-time (increased PE was not included). No evidence of improvements in mathematics skills (arithmetic's, algebra, problem-solving or geometry) or in a test of inhibition (flanker task) was found in this school-based intervention. Seven intervention schools had agreed to provide 60 minutes of PA every school day during the intervention. The teachers attended a course in incorporating PA into academic lessons. However, PA levels were not affected by the intervention, i.e. the aim of delivering 60 minutes of PA each school day was not reached. This result indicates the problem with intervention fidelity and difficulties in implementing activities in school that are not scheduled in the curriculum. Another Danish intervention study examined the effect of Movement Integrated into Teaching. There were no effects on 13-15 year-old students' reading and math scores after 12 weeks of the intervention [31].

In another RCT students had PA lessons for two years (20-30 min/lesson three times a week) consisting of PA at moderate-tovigorous intensity, e.g. jogging, hopping in place, or marching. For example, students jumped eight times to solve the multiplication ' 4 x 2', and for language, students performed a squat for every spelled letter in the word 'dog'. The control group had regular classroom lessons. Mullender-Wijnsma et al. [32] reported significantly greater gains in mathematics speed test, general mathematics, and spelling, compared to the control group. But no differences were found in a reading test, nor in any test of EF. Norris et al. [33] fond that PA lessons resulted in a small improvement in overall educational outcomes but no effect on cognitive outcomes was found. The results also suggested that PA lessons are not sufficient to improve children's BMI or fitness. In their systematic review Singh et al. [34] found no significant differences in cognition between control and intervention group after 16 months with 15 minutes of daily classroom PA.

In the Swedish curriculum it is stated that all teaching methods in school should be based on scientific evidence. In an effort to improve scholastic performance it has become quite popular in Sweden, despite lack of evidence, to use pulse-raising exercise in the classroom during regular lessons. However, seven minutes of pulseraising exercise at the beginning of each mathematic lesson showed no improvements in mathematics compared to a control group [35]. A meta-analysis by de Greeff et al. [32] showed that PA lessons did not result in any significant change in EFs. A meta-analysis by Álvarez-Bueno et.al. [4] gave the same result: Classroom-based PA do not have a positive impact on children's cognition. 


\section{Different Types of Exercise and Intensity in the Classroom}

A moderate level of PA has the potential to improve cognitive performance but additional high-intensity PA above the optimal level might decrease that performance [36,37]. Although a single session of moderate PA can have some positive effect on brain function, cognition, and scholastic performance, high stress or fatigue from too intense activity may blunt any beneficial effect [11]. In a meta-analysis Hansen et al. [38] found that larger gains in aerobic fitness from pretest to posttest were predictive of lesser improvements in cognitive performance. A nonlinear relationship was also found between fitness and spelling and mathematics scores among second- and third-year students $(n=687)$. The greatest effect on academic achievements was found for children below a particular fitness threshold compared to those above. Thus, aerobic fitness does not appear to explain a meaningful percentage of the variance in cognition. Lees and Hopkins [39] reviewed eight RCTs studying the effects of aerobic PA on cognitive performance. All studies showed a small impact on children's cognition. However, this relationship was minimal in many studies and in some measures, no significant improvement was found at all.

School children in the age of $6-9$ years $(n=465)$ from 40 different classrooms were randomized to high or low intensity PA. High intensity activities focused on elevating heart rate (e.g. running, skipping, or dancing) for a duration of up to 10 minutes. Despite that PA significantly differed in steps and time in moderate to vigorous PA between the high and low PA groups, there were no significant differences in cognitive performance between the groups in any of the cognitive tasks [40]. Moderate to vigorous exercise bouts (bicycle ergometer) with a duration of 10,20 , or 30 minutes did not improve selective attention and working memory of young adolescents, compared to a control group in which students worked on school-related tasks [41]. Children who participated in a PE class for 30 minutes however, demonstrated increased attention after the class, but not after PA in the classroom [42].

Exercise cognition research often focus quantitative factors and dose-response relations of PA levels and cognition. However, quantitative characteristics seem to have a lower impact on cognitive benefits of PA than qualitative exercise characteristics [25]. There are only few studies that have considered also qualitative relations between different types of PA and cognitive outcomes. Taking part in a classroom break of 15 minutes self-paced outdoor activity (running or walking at a speed of their own choice) was beneficial for 8-10 year old students' cognition (inhibition, visualspatial working memory and verbal working memory) compared to a beep test run (a more intense near maximal exhaustion activity), or a control activity of sitting or standing outdoors. The relationship with cognition was not impacted by the students' fitness [43]. A controlled study examined ( $n=195,10-13$-year-olds) acute effects of three different types of classroom-based exercise sessions (aerobic, coordination, and strength) in short bouts of 12 minutes in the classroom. The result showed that the exercise in the classroom did not have any effect on cognitive functions (information processing speed or selective attention) and there were no differences between exercise types [44].

The main findings from studies on PA in the classroom are not very promising. Most results show that PA lessons do not improve any EF and that classroom-based PA do not have a positive impact on children's cognition. Besides problems with intervention fidelity there is a lack of a theoretical basis as to why PA lessons may facilitate scholastic performance. Another question is what the students are supposed to learn from PA in the classroom. Qualitative aspects of motor skills used in classroom interventions are often overlooked. The role of the teacher and different teaching methods are seldom described in PA lesson studies. Although there is some evidence that a single session of moderate PA may improve cognitive performance among children, too intense activity may blunt any beneficial effect.

\section{Physical Education Interventions}

Many schools have reduced or eliminated the school subject Physical Education (PE), in an effort to increase students' academic performance. However, no empirical evidence exists to suggest that the elimination of PE is related to higher academic achievement. $\mathrm{PE}$ is an important component of children's health and wellbeing $[45,46]$, although many of the educational benefits claimed for PE programs are dependent on contextual and pedagogic variables. Type of activity, intensity levels, and psychological factors (e.g. selfesteem and motivation) could mediate the association between PE and academic performance $[17,47]$. Eleven of 14 studies in a review by Rasberrya et al. [48] found one or more positive associations between the school subject PE and indicators of academic performance. Studies in the review examined increased PE time (number of days PE was scheduled per week or lengthening class time) and/or improved quality of PE (e.g., trained instructors or increasing active time during PE class).

Preadolescent children had daily intense aerobic exercise in school, aimed at increasing cardiovascular fitness. The results after two years showed that longtime high intensity PA did not lead to any improvement in working memory or mathematics [49]. Unexpectedly, a significant increase in self-rated stress was detected in the intervention group, especially among girls. Enhancing enjoyable physical noncompetitive activities in the school curriculum may, however, yield benefits in academic achievements and psychological health of children, particularly in girls [50].

In a meta-analysis Álvarez-Bueno et al. [51] conclude that especially PE can improve several aspects of academic achievement, e.g. mathematics and reading-related skills. In interventions developed by trained PE teachers, the benefits were greater. In an experiment, motor skills activities were used to enhance children's overall development and body awareness. The children participated in a structured PE program conducted by a PE teacher. The sessions included adequate motor coordination, overall coordination, spatial structure, temporal organization, body structure, body image, body knowledge, and laterality. The control group had PA in the school 
playground, but it was not structured or conducted by a PE teacher. The results showed that test scores were significantly higher in the intervention than in the control group, for all measured abilities: Coordination and Balance, Body Scheme, Temporal Organization, and Spatial Organization [52].

Skill acquisition is a complex phenomenon that involves cognitive, affective, as well as motivational processes. Many exercise and cognition researchers fail to consider the fact that exercise training programs require participants to acquire specific motor-movement skills [53]. Morgan et al. [54] included 22 FMS intervention studies in a meta-analysis. All studies reported significant effects on motor skills performance. The authors' conclusion was that school-based programs that include developmentally appropriate FMS learning experiences, delivered by PE specialists or highly trained classroom teachers, significantly improve FMS in youth. However, a growing problem is that the increased prevalence of sedentary behavior among children and youth has influenced PE teacher education at universities [55]. Instead of mastering how to apply instructional strategies related to motor skills development, PE teachers are now primarily trained to provide opportunities for students to move, and secondarily to improve the quality of the movement. Kalaja [56] conducted a PE intervention study in Finland $(n=446)$ during 33 weeks which focused three FMS: locomotion, manipulation, and balance. The intervention group showed more positive development in these variables compared to a control group. Girls scored higher in static balance and rope jumping tests, whereas boys scored higher in dynamic balance, leaping, accuracy throwing, and dribbling tests. The study demonstrated that in secondary school PE, there is a need to emphasize teaching of students' FMS. Improved skills might be one factor to prevent the typical decline of PA within adolescence. According to Yli-Piiparia [57] the Finnish education system has received worldwide attention due to the top academic performance of Finnish school students. PE potentially contributes to the overall success; the subject has a solid foundation in Finnish schools and strong support in Finnish society.

The effects of two qualitatively different chronic PE interventions on executive functions were examined in primary school children. Children aged $10-12$ years $(n=181)$ had a sixweek PE program in three different groups; one with a high level of physical exertion and high cognitive challenges (team games), another group had PE with high physical exertion but low cognitive challenges (aerobic exercise), and a control group had PE with both low physical exertion and low cognitive engagement. EFs (updating, inhibition, shifting) and aerobic fitness (20 m shuttle run test) were measured before and after the Intervention. Results revealed that both team games and aerobic exercise improved children's aerobic fitness. But, only in the team games and not in the aerobic exercise or control group an improvement in shifting performance was found, suggesting that the cognitive engagement in PA seems to be the most promising type of chronic exercise to improve EFs in children [20]. Pesce et al. [5] conducted a large clustered RCT $(n=920)$ that compared the effects of six months of weekly PE games that emphasized variability of practice and contextual interference with traditional PE instruction. Only children who participated in the combined PE and motor skill training condition improved in inhibitory control. Intervention effects on ball control benefited children's inhibitory control and suggested that visuomotor experiences challenged and honed interceptive and planning processes. These results support the cognitive stimulation theory and provide further evidence for the importance of the qualitative aspects of PE and PA interventions.

In 39 intervention studies Fedewa and Ahn [58] found significant effects on children's academic achievement and cognitive outcomes from perceptual motor training, regular PE classes and aerobic training. No significant effects were found from resistance/circuit training on children's achievement and cognitive outcomes. Significantly higher effect sizes were found when PA was provided three compared to two times per week. Elementary school age children were found to benefit the most. Cognitively impaired or physically disabled children appeared to benefit even more than typically developing children. Dalziella et al. [59] found lasting cognitive and coordination improvements after a PE intervention including fundamental locomotor skills (crawling, creeping, marching and skipping). These results are in line with the findings in the Swedish Bunkeflo project where Ericsson and Karlsson [2] studied long-term effects on motor skills and scholastic performance of daily PE (5x45 minutes/week) and adapted MUGI motor skills support (Figure 1) for children in need of it. Significant improvements were found in reading, writing and mathematics in the intervention compared to a control group [17]. After nine years of intervention $96 \%$ of the students compared to $89 \%$ in the control group qualified for upper secondary school. The intervention was an effective way to improve not only motor skills but also scholastic performance. Health-economic analyses show that daily PE and MUGI motor skills exercise would give society gains (reduced morbidity costs and productivity gains) of 38,000 SEK (Euro 4,130) per student ten years after leaving school [60].

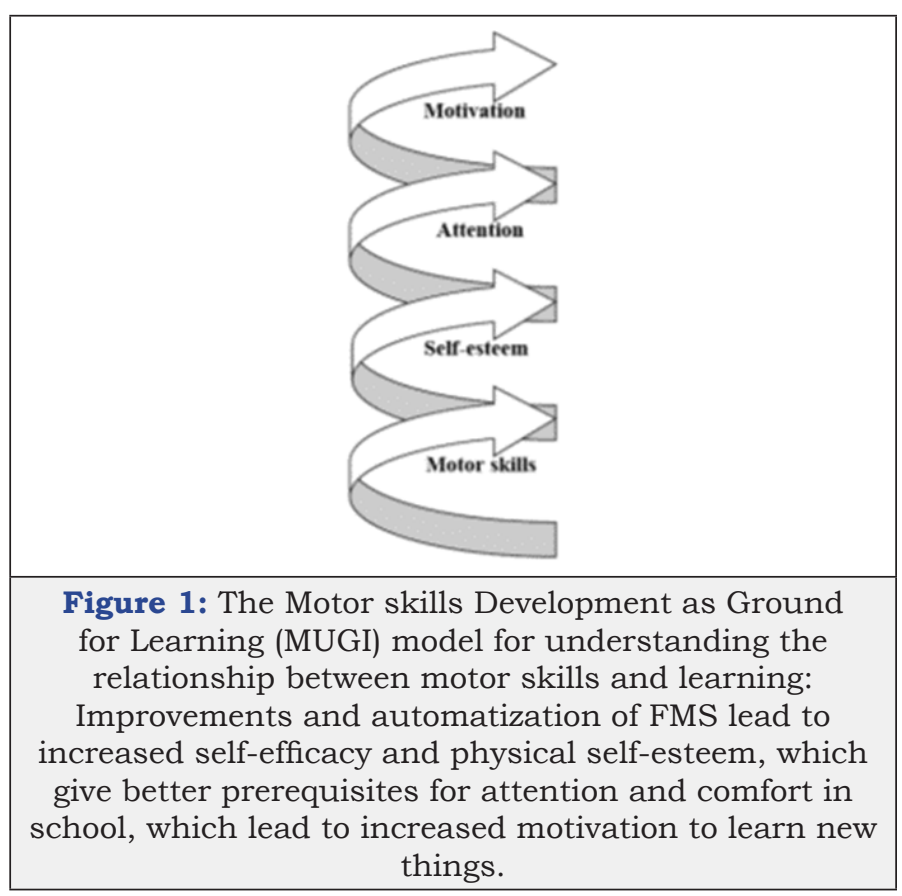


A Danish study investigated the influence of six compared to two PE lessons per week, but no significant differences were observed between groups in the academic performance tests (mathematics and Danish) [47]. An explanation could be that since the extra PE lessons resulted in longer school days for students in the intervention group they might have experienced cognitive fatigue, and thus did not improve more in scholastic performance than students in the control group [61].

The main findings of PE intervention studies indicate that increased PE which include motor skills exercise can positively influence children's and adolescents' motor skills and scholastic performance, especially when interventions are developed by trained PE teachers. High intensity PA with a high level of physical exertion does not improve cognitive function in children. Cognitive engagement in PA at a moderate level seems to be the most promising type of exercise. Health-economic analyses show that daily PE and MUGI motor skills exercise would give society gains (reduced morbidity costs and productivity gains).

\section{Conclusion}

Compulsory school curricula have a great potential in offering PA to all children. There is limited and inconclusive evidence regarding effects of different PA interventions in school on cognitive functioning and scholastic performance. Moderate levels of PA with cognitive challenges are more effective than aerobic exercise. There is a strong association between motor competence and scholastic performance. PE interventions which include motor skills exercise seem to be more promising than PA in the classroom. Motor skills assessment early in school is associated with later school achievement and can be used as an indicator of children's future scholastic performance. Daily PE and adapted MUGI motor skills training can positively influence motor skills, higher grades and higher proportions of pupils who reach qualification for higher education. In addition the investment can be health-economically profitable for the society. Well educated PE teachers are essential for translating research findings into practice since they can properly design motor skill observations, PE programs, and motor skill programs in order to optimize their effect on children's cognition and scholastic performance.

\section{Implications and Recommendations}

Although PA is beneficial at all stages of life, early interventions might be important for the improvement and/or maintenance of FMS and cognitive health. Individuals who master different motor skills tend to have an improved basis for participation in various sports and PA games [13], and as a consequence also increase their fitness and PA levels [58].

Moderate levels of PA which include motor skills exercise is recommended since it seems to have the greatest benefit and high intensity PA levels might impair cognitive performance. PA immediately prior to a learning session should therefore not be too intense since high stress or fatigue may blunt the beneficial effect. Exercise at high intensity may be important to improve physical fitness, but not cognitive functions. The cognitive components of the PA might be the main contributors to any EF benefit. Learning to perform a complex motor skill, e.g. to play a new ball game or execute a complex dance step is cognitively challenging and involves a lot of practice, but with relatively low levels of physical exertion. Physiological or psychological mechanisms that are affected by PA participation, but not by changes in cardiovascular fitness may be responsible for the benefits in cognitive performance [59].

PE and qualified PE teachers are important in child development. The role of teacher education is important in the development of motor skill competency in children. Teachers who receive training in PE should learn how to offer cognitively challenging PA that require FMS. For many children and youths, school curriculum is the only way they can receive PA on a daily basis. Daily PE in combination with adapted motor skills training during the compulsory school years has shown to be a feasible way to improve not only motor skills but also academic achievements [2,17]. Motor skills screening can contribute to predict children's cognitive preparedness for school and is recommended since it also provides a valuable tool for identifying children in need of adapted support in motor skill development. Specific interventions are needed for children with learning disabilities, programs that facilitate both motor skills and academic abilities $[8,11]$.

\section{Challenges for Future Research}

There is a need to synthesize the evidence regarding brain and motor control to provide a framework for a sustainable and life-long interest in physical activity. Future intervention studies specifically designed to test the dose-response relationship between cardiorespiratory exercise compared to motor skills exercise and scholastic performance are needed. It is important to consider qualitative relations between different types of PA and cognitive outcomes. Intensity levels are usually measured in PA research (e.g. aerobic, endurance or resistance exercise), whereas complexity levels might be more appropriate to regulate the demands of motor skills. However, studies that have investigated effects of motor skills on cognitive function have seldom used measurements to assess complexity levels in motor skills exercise. Consensus regarding the concept Fundamental Movement Skills (FMS) is needed, as well as how to measure different parts of motor skills.

Several important research questions still need to be examined, e.g. what is the best method for improving FMS? How important are cognitive challenges in motor skills and/or aerobic training? Very interesting is whether or how intervention schools have included special needs education in motor skills and if they have offered adapted support in motor skills development to children in need of it. Emotional and motivational outcomes, e.g. enjoyment and self-efficacy in motor competence might be relevant moderators or mediators of PA effects.

Results from studies on PA in the classroom are not very promising. Although there is some evidence that acute exercise may improve cognitive performance among children, interventions in the classroom have produced mixed results. Besides problems with intervention fidelity there is a lack of a theoretical basis as to why PA lessons may facilitate scholastic performance. Another question 
is what the students are supposed to learn from physical activities in the classroom. The role of the teacher and different teaching methods are often overlooked in PA lesson studies and need to be examined.

In addition, there is a need for more PE and adapted motor skills studies conducted in school settings. Evidence is still too sparse to conclude whether an increase of PE lessons or changes in teaching methods is most effective for improving scholastic performance. In school-based interventions it is important to clearly separate effects of different PE programs, from those of PA lessons or extended recess time. Robust studies, i.e. RCT, and meta-analyses are needed to provide evidence of the efficacy and effectiveness of different PE programs and motor skills interventions.

\section{References}

1. Singh AS, Saliasi E, van den Berg V, Uijtdewilligen L, de Groot RH, et al. (2018) Effects of physical activity interventions on cognitive and academic performance in children and adolescents: A novel combination of a systematic review and recommendations from an expert panel. British Journal of Sports Medicine 53(10).

2. Ericsson I, Karlsson M (2014) Motor skills and school performance in children with daily physical education in school - a nine-year intervention study. Scand J Med Sci Sports 24(2): 273-278.

3. Diamond A, Ling D (2018) Aerobic-Exercise and resistance-training interventions have been among the least effective ways to improve executive functions of any method tried thus far. Dev Cogn Neurosci 37: 100572.

4. Álvarez-Bueno C, Pesce C, Cavero-Redondo I, Sánchez-López M, MartínezHortelano J (2017a) The effect of physical activity interventions on children's cognition and metacognition: A systematic review and metaanalysis. J Am Acad Child Adolesc Psychiatry 56(9): 729-738.

5. Pesce C, Masci C, Marchetti R, Vazou S, Sääkslahti A (2016) Deliberate play jointly benefits motor and cognitive development: Direct and indirect effects of cognitive stimulation by movement. Frontiers in Psychology 7: 349 .

6. Robinson LE, Stodden DF, Barnett LM, Lopes VP, Logan SW, et al. (2015) Cognitively engaging chronic physical activity, but not aerobic exercise, affects executive functions in primary school children: A grouprandomized controlled trial. J Sport Exerc Psychol 37(6): 575-591.

7. Schmidt M, Egger F, Benzing V, Jäger K, Conzelmann A (2017) Disentangling the relationship between children's motor ability, executive function and academic achievement. PLoS ONE 12(8): 1-19.

8. Westendorp M, Hartman E, Houwen S, Smith J, Visscher C (2011) The relationship between gross motor skills and academic achievement in children with learning disabilities. Res Dev Disabil 32(6): 2773-2779.

9. Ludyga S, Herrmann C, Mücke M, Andrä C, Brand S (2018) Contingent negative variation and working memory maintenance in adolescents with low and high motor competencies. Neural Plasticity 1-10: 9628787.

10. Vedul-Kjelsås V, Stensdotter AK, Sigmundsson H, Haga M (2015) Physical fitness, self-perception and physical activity in children with different motor competence. European Journal of Adapted Physical Activity, 8(1): 45-57.

11. Bangsbo J, Krustrup P, Duda J, Hillman C, Andersen LB (2016) The copenhagen consensus conference 2016 - children, youth, and physical activity in schools and during leisure time. Recommendations. Copenhagen: Copenhagen Centre for Team Sport and Health, Department of Nutrition, Exercise and Sports, University of Copenhagen.

12. Tomporowski PD, Davis CL, Miller PH, Naglieri JA (2008) Exercise and children's intelligence, cognition, and academic achievement. Educational Psychology Review 20(2): 111-131.
13. Draper C, Achmat M, Forbes J, Lambert E (2012) Impact of a communitybased programme for motor development on gross motor skills and cognitive function in preschool children from disadvantaged settings. Early Child Development and Care 182(1): 137-152.

14. Zeng N, Ayyub M, Sun H, Wen X, Xiang P, et al. (2017) Effects of physical activity on motor skills and cognitive development in early childhood: a systematic review. Biomed Res Int 2017: 2760716.

15. Macdonald K, Milne N, Orr R, Pope R (2018) Relationships between motor proficiency and academic performance in mathematics and reading in school-aged children and adolescents: a systematic review. Int J Environ Res Public Health 15(8): 1603.

16. Son SE, Meisels S (2006) The relationship of young children's motor skills to later reading and math achievement. Merrill-Palmer Quarterly 52(4): 755-778.

17. Ericsson I (2003) Motor skills, attention and academic achievements - An intervention study in school years 1-3. Doctoral Thesis. School of Education, Malmö University, Lund University, Malmö.

18. Oberer N, Gashaj V, Roebers CM (2018) Executive functions, visual-motor coordination, physical fitness and academic achievement: Longitudinal relations in typically developing children. Human Movement Science 58: 69-79.

19. de Bruijn AG, Kostons DD, van der Fels IM, Visscher C, Oosterlaan J, et al. (2019) Importance of aerobic fitness and fundamental motor skills for academic achievement. Psychology of Sport \& Exercise 43: 200-210.

20. Schmidt M, Jäger K, Egger F, Roebers CM, Conzelmann A (2015) Cognitively engaging chronic physical activity, but not aerobic exercise, affects executive functions in primary school children: a grouprandomized controlled trial. Journal of Sport and Exercise Psychology 37(6): 575-591.

21. de Greeff JW, Bosker RJ, Oosterlaan J, Visscher C, Hartman E (2018) Effects of physical activity on executive functions, attention and academic performance in preadolescent children: a meta-analysis. J Sci Med Sport 21(5): 501-507.

22. Koutsandréou F, Wegner M, Niemann C, Budde H (2016) Effects of motor versus cardiovascular exercise training on children's working memory. Medicine and Science in Sports and Exercise 48(6): 1144-1152.

23. Sjöwall D, Thorell LB, Mandic M, Westerståhl M (2019) No effects of a long-term physical activity intervention on executive functioning among adolescents. SAGE Open Medicine (7): 1-7.

24. Budde H, Voelcker-Rehage C, Pietraßyk-Kendziorra S, Ribeiro P, Tidow G (2008) Acute coordinative exercise improves attentional performance in adolescents. Neurosci Lett 441(2): 219-223.

25. Ludyga S, Gerber M, Pühse U, Looser VN, Kamijo K (2020) Systematic review and meta-analysis investigating moderators of long-term effects of exercise on cognition in healthy individuals. Nat Hum Behav 4(6): 603-612.

26. Van der Fels IM, te Wierike SC, Hartman E, Elferink-Gemser MT, Smith J, et al. (2015) The relationship between motor skills and cognitive skills in 4-16 year old typically developing children: A systematic review. Journal of Science and Medicine in Sport 18(6): 697-703.

27. Rathore A, Lom B (2017) The effects of chronic and acute physical activity on working memory performance in healthy participants: a systematic review with meta-analysis of randomized controlled trials. Syst Rev 6(124).

28. Centers for Disease Control and Prevention (2010) The association between school-based physical activity, including physical education, and academic performance. Department of Health and Human Services, Georgia, Atlanta, USA.

29. Howie E, Schatz J, Pate R (2015) Acute effects of classroom exercise breaks on executive function and math performance: a dose-response study. Research Quarterly for Exercise and Sport 86: 217-224. 
30. Tarp J, Domazet SL, Froberg K, Hillman CH, Andersen LB, et al. (2016) Effectiveness of a school-based physical activity intervention on cognitive performance in danish adolescents: lcomotion-learning, cognition and motion - a cluster randomized controlled trial. PLoS One 11(6): e0158087.

31. Løgstrup Ottesen C, von Seelen J (2019) Physically active lessons in secondary school. An Intervention Study. Idrottsforum.org.

32. Mullender-Wijnsma MJ, Hartman E, de Greeff JW, Doolaard S, Bosker RJ, et al. (2016) Physically active math and language lessons improve academic achievement: a cluster randomized controlled trial. Pediatrics 137(3): 1-9.

33. Norris E, van Steen T, Direito A, Stamatakis E (2019) Physically active lessons in schools and their impact on physical activity, educational, health and cognition outcomes: a systematic review and meta-analysis. British Journal Sports Med 54(14).

34. Singh AS, Uijtdewilligen L, Twisk JWR, van Mechelen W, Chinapaw MJM (2012) Physical activity and performance at school: a systematic review of the literature including a methodological quality assessment. Arch Pediatr Adolesc Med 166(1): 49-55.

35. Balan A, Green J (2019) The effect of physical activity in maths teaching. Forskning om undervisning och lärande 3(7): 6-27.

36. Esteban-Cornejo I, Hallal PC, Mielke GI, Menezes AM, Gonçalves H, et al. (2015) Physical activity throughout adolescence and cognitive performance at 18 years of age. Med Sci Sports Exerc 47(12): 25522557.

37. Kashihara K, Maruyama T, Murota M, Nakahara Y (2009) Positive effects of acute and moderate physical exercise on cognitive function. J Physiol Anthropol 28(4): 155-164.

38. Hansen D, Herrmann S, Lambourne K, Lee J, Donnelly J (2014) Linear/ nonlinear relations of activity and fitness with children's academic achievement. Med Sci Sports Exerc 46(12): 2279-2285.

39. Lees C, Hopkins J (2013) Effect of aerobic exercise on cognition, academic achievement, and psychosocial function in children: a systematic review of randomized control trials. Preventing Chronic Disease 10: 1-8.

40. Beddoes Z, Castelli DM, Barcelona JM (2020) Acute physical activity and cognitive performance among elementary school children. Translational Journal of the ACSM 5(3): 21-28.

41. Van den Berg V, Saliasi E, Jolles J, de Groot RH, Chinapaw MJ, et al. (2018) Exercise of varying durations: no acute effects on cognitive performance in adolescents. Front Neurosci.

42. Kubesch S, Walk L, Spitzer M, Kammer T, Lainburg A, et al. (2009) A 30-minutephysical education program improves students' executive attention. Mind Brain Educ 3(4): 235-242.

43. Booth JN, Chesham RA, Brooks NE, Gorely T, Moran CN (2020) A citizen science study of short physical activity breaks at school: improvements in cognition and wellbeing with self-paced activity. BMC Medicine 18(1): 62.

44. Van den Berg V, Saliasi E, de Groot RH, Jolles J, Chinapaw MJ, et al. (2016) Physical activity in the school setting: cognitive performance is not affected by three different types of acute exercise. Front Psychol.

45. Hillman CH, Erickson K, Kramer AF (2008) Be smart, exercise your heart: exercise effects on brain and cognition. Nat Rev Neurosci 9(1): 58-65.

46. Bugge A, Möller S, Tarp J, Hillman CH, Antunes R, et al. (2018) Influence of a 2- to 6-year physical education intervention on scholastic performance: The CHAMPS study-DK. Scandinavian Journal of Medicine \& Science in Sports 28(1): 228-236.
47. Bailey R, Armour K, Kirk D, Jess M, Pickup I, et al. (2009) The educational benefits claimed for physical education and school sport: an academic review. Research Papers in Education 24(1): 1-27.

48. Rasberrya C, Leea S, Robina L, Larisb B, Russellb L, et al. (2011) The association between school-based physical activity, including physical education, and academic performance: A systematic review of the literature. Preventive Medicine 52(Suppl 1): 10-20.

49. Sjöwall D, Hertz M, Klingberg T (2017) No long-term effect of physical activity intervention on working memory or arithmetic in preadolescents. Front Psychol (8): 1342.

50. Bunketorp Käll L, Malmgren H, Olsson E, Lindén T, Nilsson M (2015) Effects of a curricular physical activity intervention on children's school performance, wellness, and brain development. Journal of School Health 85(10): 704-713

51. Álvarez-Bueno C, Pesce P, Cavero-Redondo I, Sánchez-López M, GarridoMiguel M, et al. (2017b) Academic Achievement and Physical Activity: A Meta-analysis. Pediatrics 140(6): e20171498.

52. Costa H, Abelairas-Gomez C, Arufe-Giraldez V, Barcala-Furelos R (2015) The influence of a structured physical education plan on preschool children's psychomotor development profiles. Australasian Journal of Early Childhood 40(2): 68-77.

53. Tomporowski PD, Pesce C (2019) Exercise, sports, and performance arts benefit cognition via a common process. Psychological Bulletin 145(9): 929-951.

54. Morgan PJ, Barnett LM, Cliff DP, Okely AD, Scott HA, et al. (2013) Fundamental movement skill interventions in youth: a systematic review and meta-analysis. Pediatrics 132(5): 1361-83.

55. Castelli DM (2019) Motor performance or opportunities to move? What do children need the most? J Sport Health Sci (8) 149-152.

56. Kalaja S (2012) Fundamental movement skills, physical activity, and motivation toward finnish school physical education. a fundamental movement skills intervention. Studies in sport, physical education and health 183. Doctoral Thesis. The Faculty of Sport and Health Sciences of the University of Jyväskylä, Jyväskylä.

57. Yli-Piiparia S (2014) Physical education curriculum reform in finland. Quest 66(4): 468-484.

58. Fedewa AL, Ahn S (2011) The effects of physical activity and physical fitness on children's achievement and cognitive outcomes: a metaanalysis. Research quarterly for exercise and sport 82(3): 521-535.

59. Dalziella A, Bootha JN, Boyleband J, Mutrieaa N (2019) Better movers and thinkers: an evaluation of how a novel approach to teaching physical education can impact children's physical activity, coordination and cognition. British Educational Journal 45(3): 576-591.

60. Gerdtham U, Ghatnekar O, Svensson M (2013) Health economics evaluations - basic data for the Commission for a Socially Sustainable Malmö. Commission for a Socially Sustainable Malmö, Malmö.

61. Sievertsen HH, Gino F, Piovesan M (2016) Cognitive fatigue influences students' performance on standardized tests. Proc Natl Acad Sci USA 113(10): 2621-2624.

62. Haga M, Haapala EA, Sigmundsson H (2020) Physical fitness. growth in childhood health. The Encyclopedia of Child and Adolescent Development.

63. Watson A, Timperio A, Brown H, Best K, Hesketh K (2017) Effect of classroom-based physical activity interventions on academic and physical activity outcomes: a systematic review and meta-analysis. Int J Behav Nutr Phys Act 14(114).

For possible submissions Click below:

Submit Article 